\title{
Title: Unemployment and Attitudes to Work: asking the 'right' question
}

\begin{abstract}
Attitudes research has repeatedly demonstrated that the vast majority of unemployed people want a job, and that their work commitment is generally at least as strong as employed people's. But until now it has not asked if they are more likely than employed people to prefer unemployment to an unattractive job. While this oversight reflects a noted widespread reluctance to respond directly to right-wing authors' assertions, this article argues that it is partly attributable to existing studies using survey questions inappropriate for researching unemployment. Responses to the British Cohort Study / National Child Development Study agree / disagree statement 'having almost any job is better than being unemployed' were analysed. Being 'unemployed and seeking work' associated strongly with disagreeing with the statement across all recent datasets in both studies, even when a number of relevant variables were controlled for.
\end{abstract}

\section{Keywords}

attitudes / employment commitment / jobseeker's allowance / unemployment / work ethic

\section{Introduction}

Long-term Jobseeker's Allowance (JSA) claimants must participate in the Work Programme, which gives voluntary or private sector organisations contracts to support people back into employment, or face the most severe benefit sanctions imposed on the unemployed in the history of the UK Welfare State (Wright, 2012). While the coalition government might consider such measures necessary to ensure unemployed people look for jobs, existing evidence, gathered mainly in the 1980s and 1990s, strongly suggests that the vast majority of unemployed people want to escape living on benefits. This evidence includes studies of unemployed people's reported job search behaviour (e.g. Trickey et al., 1998), their supposed 'dependency' upon welfare benefits (e.g. Dean and Taylor-Gooby, 1992) and this article's focus - their attitudes to work. Survey research demonstrated that over 90 per cent of unemployed people wanted employment and that many of them were willing to do low paid, weekend and shift work (e.g. McKay et al, 1997, using Department of Social Security data). Some major surveys even found that unemployed people expressed more positive attitudes towards employment than employed people. When asked the 'lottery question' - would they choose to work if they had no financial need to? -significantly more unemployed than employed people said they would (Gallie and Vogler, 1994). Hence, Walker's (2000: 97) review of unemployment literature was able to conclude that 'the evidence is clear that very few unemployed claimants prefer welfare benefits to a job', and his conclusion is echoed by recent research (e.g. Shildrick et al., 2012).

Nevertheless, important questions have remained unanswered. In the 1980s and 1990s, some conservative authors claimed that large numbers of unemployed people remained on benefits because they were unwilling to do unattractive or badly paid jobs (Mead, 1988; Murray, 1990; Marsland, 1996). But they were not responded to in detail by mainstream social policy authors (Deacon and Mann, 1999), perhaps because their evidence was only anecdotal and therefore not 
taken seriously (Townsend, 1993), or perhaps for political reasons. As Deacon (2002: 22-26) noted, left-dominated UK social policy academia's strong emphasis on structural explanations of social problems had extended into a 'denial of agency', whereby any focus on sub-cultures or the actions of individuals when explaining poverty was castigated for 'blaming the victim'. Furthermore, as Mead (1988: 48) observed, left-of-centre authors typically deem the question of whether or not unemployed claimants are avoiding unattractive jobs irrelevant because, unlike conservatives, their overriding concern for social justice means they only insist claimants apply for jobs that are 'attractive as well as legal'. Thus, neither side undertook an empirical investigation into whether or not unemployed people are generally more likely than employed people to prefer unemployment to an unattractive job.

The research presented in this article set out to answer precisely this question by analysing responses to the agree / disagree survey item 'having almost any job is better than being unemployed' in the most recent waves of major surveys to include it - the 1996 and 2000 British Cohort Study and the 2000 and 2008 National Child Development Study. British Cohort Study respondents were born in 1970 and National Child Development Study respondents in 1958, so the studies are hereon referred to as BCS70 and NCDS58. This survey item was chosen because it gives respondents a choice between what they consider to be 'almost' the least attractive job and being unemployed (thus, what constitutes an 'unattractive' job is decided by respondents). We controlled for other relevant variables (both socio-demographic and values) in ordered probit models to discover whether any association between being unemployed and preferring 'being unemployed' was driven by factors associated both with being unemployed and with preferring being unemployed. Examining these other variables is important because the unemployed category is weighted so heavily in favour of people with particular characteristics - notably being young, male, black, working class and having fewest educational qualifications (see, for example, Gregg and Wadsworth eds., 2011; Trickey et al., 1998). Thus, the key hypothesis we test in this article is that unemployed people are more likely than employed people to disagree with the statement that 'having almost any job is better than being unemployed', even when other relevant variables are controlled for.

The next section looks at existing literature on attitudes towards unemployment and employment (focusing mainly on less attractive forms of employment). It starts with an examination of how attitudes to employment vary across socio-demographic groups. However, we argue that some existing quantitative evidence needs to be re-examined because, to date, studies exploring attitudes to employment have failed to use survey questions that offer respondents the chance to express a preference for unemployment versus an unattractive job. Our choice of survey item / dependent variable is then defended with reference to research which tested its meaning qualitatively with 70 interviewees. Findings from ordered probit regression models analysing data from the BCS70 / NCDS58 are then presented. A conclusion follows.

\section{Existing academic work on attitudes towards employment and unemployment}

Socio-Demographic 'Groups' and Attitudes to Work

Attempting to piece together existing studies' findings to form a picture of how sociodemographic groups vary in their attitudes towards unemployment and employment (in particular, 
unattractive jobs) is not straightforward, for several reasons. First, studies have rarely set out to address this exact question. Second, the literature stretches far back in time, so some findings might no longer apply. Finally, membership of these supposed 'groups' in fact overlaps considerably - individuals possess multiple socio-demographic characteristics, so it is hard to pin down the characteristic that accounts for their preferences. Hence, while some common findings relevant to our central research question can be discerned, much remains unclear or contradictory.

Numerous in-depth studies carried out in the 1970s and 1980s identified the breadwinnerhomemaker model as the dominant normative framework for assigning work roles, with working class men taking a masculine pride in tough manual employment and suffering greatly when unemployed due to a loss of social identity and a lack of replacement activities (examples include Marsden, 1982; Jordan et al., 1992). While the breadwinner-homemaker model is no longer prevalent, recent in-depth studies have nevertheless found that class-based and gendered cultural norms continue to exert a heavy influence upon employment decisions (Atkinson, 2010; Shildrick et al., 2012). Class culture shone through in the findings of a qualitative study with the same central research question as this article (Author A). Working class 'traditionalist' male respondents' strong preference for masculine, working class jobs over unemployment reflected both their class-based socialisation and their lack of education. However, this and other studies (e.g. Jordan et al., 1992) found that these men are inclined to reject work paying no more than benefits and often refuse what they consider 'women's work', which might help explain the survey finding that they often eschew entry-level service sector jobs (Lindsay and McQuaid, 2004). Thus, it is hard to draw firm conclusions about the overall pattern of preferences for unattractive jobs and being unemployed for gender and social class. Author A's main finding was that the more educationally qualified, whether male or female, were usually the least attracted to the intrinsic rewards, social opportunities and small economic gains offered by low status jobs, and, as McRae's (1987) qualitative study of young unemployed people also found, they reported feeling least bored when unemployed due to activities such as reading, and least ashamed because their education steered them away from blaming themselves.

Of the other socio-demographic groups, some studies have found that people at the periphery of working age are likelier to prefer unemployment to employment - young adults because often they have no dependents, are as yet unaccustomed to employment, and have friends who are also unemployed (Pahl's 1994 in-depth work), and the nearly-retired because they have 'done their stint' in employment and are therefore absolved from negative judgement when unemployed (White's 1991 survey work). Some interview research has found that employers believe migrants are often keener than locals to undertake low paid jobs (Glossop and Shaheen, 2009). Finally, indepth research has found that having dependents can push people towards seeing securing a substantial income through employment as imperative (Author, B).

So we can, albeit tentatively, draw some conclusions from existing empirical work: The less educationally qualified (who are at considerable risk of unemployment) appear to favour unattractive jobs over unemployment to a greater extent than the more educationally qualified; people with dependents sometimes favour employment more than those without (at least if it increases their net income substantially); and the middle-aged appear to favour employment (in general) more than both the youngest adults and the nearly retired (though this might perhaps 
reflect, to some extent, their generally higher chances of securing highly paid and intrinsically rewarding jobs). These conclusions informed our choice of variables for the research presented later. A key reason why these conclusions are so limited in number is that, as we explain next, quantitative research has used survey items unsuitable for testing our key hypothesis.

\section{Survey Measures of Attitudes to Work}

Debates about unemployment and attitudes to work have proceeded without any discussion of how survey questions are worded. As we now argue, researchers have routinely deployed survey questions incapable of discovering if people prefer unemployment to an unattractive job, so the evidence delivered by these existing studies is therefore worth re-examining. Attitudes towards work or employment are mostly measured using the 'lottery question' or Protestant Work Ethic (PWE) scales, which we discuss in turn.

The 'lottery' or 'millionaire' question asks respondents to imagine that they do not need an income, and then to decide if they would choose to work in this circumstance:

'If you were to get as much money to live as comfortably as you would like for the rest of your life, would you continue to work, not necessarily in your present job?'

This measure attracts more 'yes's' from the more educationally qualified than it does from the less qualified (e.g. Rose, 2005) and more yes's from the higher social classes than lower ones (e.g. Gallie and White, 1993). However, we suggest that these findings might reflect these groups' enjoyment of their typically more intrinsically rewarding jobs, as we might expect they had their usual jobs in mind when answering, particularly as they were asked if they would 'continue to work'. We know of no in-depth study that substantiates the finding that there is a relatively low commitment to work among the less educated or the working class[i].

The PWE is widely considered to be a multi-faceted concept accommodating not only work values, but also deferred gratification, asceticism, authority, thrift, and the view that the distribution of economic rewards in society is essentially fair (see Furnham, 1990). The most commonly used PWE measure is Mirels and Garrett's (1971: 41) 19-item scale - (for example, Hassall et al., 2005 used it in finding a similar work ethic among employed and unemployed Australians). While the scale features all PWE facets, its main emphasis is on a moral stance which favours work (though what kind and whether it is paid or unpaid is unclear) over leisure. Below are examples of agree / disagree items from the scale:

I feel uneasy when there is little work for me to do.

Most people spend too much time in unprofitable amusements.

Most people who don't succeed in life are just plain lazy.

Given the PWE items' moralising tone, it is perhaps unsurprising that the scale delivers a high level of agreement among groups known to be generally less liberal - notably (and in contrast to 
the 'lottery question') the less educationally qualified (Tang and Tzeng, 1992) and conservatives (Furnham and Bland, 1983).

While the PWE scales and 'lottery question' are both arguably unsuitable for studying unemployment as they do not offer a choice even between being employed, per se, and being unemployed, our chosen measure offers a choice between an unattractive job and unemployment. The next section starts by further defending our choice of survey item.

\section{Methodology}

In 2011, Author D asked 40 unemployed and 30 employed people to respond to our chosen agree / disagree survey item ('having almost any job is better than being unemployed'), and then asked them the reasons for their response and what they believed the survey item meant.[ii] These interviews gave strong support to the view that the survey item holds job quality constant and low, but not too low, so that respondents are likely to assume 'almost any job' means what they perceive to be perhaps something like the ninth best job out of every ten in the UK labour market. For example, a female interviewee (age 39, unemployed) said she took it to mean 'practically any job, near-enough any job'. Thus, respondents indicated that while the measure holds job quality low enough for it to be relevant to the right-wing claims about unemployment and less attractive jobs discussed earlier, it is unlikely to elicit responses that indicate aversion to extremely unattractive jobs, or jobs which are wholly unsuitable for particular individuals. This is an important consideration in debates about unemployment, as even the most ardent conservatives might not insist they apply for such jobs. All respondents, including those with generally very positive attitudes to low status jobs usually indicated that there were some extremely unattractive jobs they believed they would dislike more than being unemployed. Thus, 'agreers' often said that if the survey item had not included the word 'almost' they would have 'disagreed'. While the 70 interviews suggested that findings based on this survey item might, to some extent, reflect respondents' perceptions of what 'bad' jobs and unemployment are like rather than their lived experience, the same is often true of actual labour market choices - people often choose to seek or avoid certain kinds of work (or unemployment) even if they have not already experienced them (Author A). Indeed, interviewees' responses to the survey item broadly matched their actual reported labour market choices, with the notable exception of eight cases. The eight said their answers reflected what they felt people generally should do when choosing between 'almost any job' and 'being unemployed' - not their own personal preferences. For example, female, 44, unemployed, defended her 'neither agree nor disagree' response by saying 'I think it depends on the person'. She then explained 'I was thinking [about] people generally'.

In order to use the same sample across the two waves of each survey (BCS70 1996 and 2000, and NCDS58 2000 and 2008), observations with missing values on any of the variables used in the analysis were deleted. Total sample sizes in the clean data set are 5,363 for the BCS70 (both 1996 and 2000) and 5,505 for the NCDS58 (both 2000 and 2008). These datasets have been chosen for analysis because they contain a number of comparable variables[iii] and, crucially, the outcome variable, which discerns preference for 'almost any job' over 'being unemployed'. Analysing these four datasets allows individuals from two different cohorts, each at two different stages of their life course - age 26 and 30 (BCS70 respondents) and 42 and 50 (NCDS58 respondents) - to be studied. This approach makes it possible to observe the extent to which the same results hold 
for each cohort at two different points in time (and therefore test for the robustness of results in different labour market and policy contexts).[iv] However, while we are able to see the effect of time in the analysis to some extent, the study does not examine whether attitudes in one wave of the survey impact on outcomes in another wave (for example, what were the attitudes of BCS70 respondents who were unemployed in 2000 towards 'almost any job' in 1996?) Preliminary analysis of the datasets found these associations between attitudes and employment statuses in different waves of the same survey are significant, though weaker (usually by about half) than associations for the same year[v]. This finding is consistent with an in-depth study which found that individuals' attitudes, along with their actual labour market choices, sometimes changed considerably during their lives (Author, D). Given these changes, it is crucial to present analysis focusing on particular points in time when posing our research question.

The analysis applies ordered probit models to test which factors - in addition to employment status - are associated with the outcome variable. The outcome variable has been re-coded on a scale of 1 to 5, where the highest score denotes strong agreement that 'having almost any job is better than being unemployed' (hereon referred to by the shorthand term 'almost any job'). Thus, positive coefficients in the models signify a stronger preference for 'almost any job', and negative coefficients signify a strong preference for 'being unemployed'. Predictor variables are selected partly on the basis of previous literature and partly from an initial descriptive / exploratory analysis of the four datasets. This initial statistical analysis examined numerous values / attitudes, socio-demographic and lifestyle variables that appeared in all four datasets, to discover whether or not they associated significantly with employment status and with preferring 'almost any job'. Given the lack of solid conclusions emerging from the article's literature review, and the essentially exploratory nature of the study, this initial analysis was important in determining the choice of variables for the ordered probit models, though all included variables are of some theoretical interest.

In fact, all variables that emerged as important in either the literature review or the descriptive / exploratory analysis are included in the analysis[vi]. Of the three variables that emerged as important in the literature review, only age was not directly estimable as a parameter for the ordered probit models. However, we attempted to draw some conclusions about the effect of age indirectly, by comparing responses in different waves (though, with all survey respondents aged between 26 and 50, this is unable to add to the existing findings about the nearly-retired and very young adults reported on page 6). The other two variables to emerge from the literature review education and whether or not people have dependent children - both also emerged as significant in the initial statistical analysis, in the way predicted by those studies' findings (see Appendix) and are included in the models (household size is used as a proxy for the number of dependent children, in the absence of directly comparable measures across the studies). Gender, which associated with being unemployed but not with preferring 'almost any job', is included because it is an important socio-demographic characteristic and findings about gender might shed light on some of the issues discussed in the literature review. It was not possible to include two other interesting variables - country of origin and socio-economic status. While both are important to the composition of the unemployed category and might be expected to deliver distinct patterns of attitudes, numbers of ethnic minority and migrant respondents in the BCS70 and NCDS58 are notoriously low (Mokhtar and Platt, 2010), while attempting to include class from the previous / subsequent wave would have resulted in losing of over $50 \%$ of the cases. 
The full list of covariates included in the models is as follows: unemployment $(1=$ 'unemployed and seeking work', $0=$ 'employed')[vii]; gender ( $1=$ male, $0=$ female); household size (a continuous variable); tenure (owner, mortgage, rent or other); education (highest educational qualification achieved), a measure of self-reported health (health), reported extent of smoking and drinking, and three political / social value scales: left-right and measures of authority and morality.

Home owners and people with a mortgage are expected to be more likely than renters (measured by tenure) to prefer 'almost any job' because they risk losing their property if they lose their job, while renters often forfeit Housing Benefit on entering employment (this view was not mentioned in the literature review because we know of no empirical study that has compared renters' and mortgagers' attitudes). Education is an important variable to control for as, uniquely, the more qualified are both more likely to prefer 'being unemployed' and more likely to be employed. There are three health-related variables - a measure of self-reported health (health), and reported extent of smoking and drinking.[viii] It is perhaps unsurprising that poorer self-reported health associated with both being 'unemployed and seeking work' and preferring 'being unemployed', as it might lower work motivation and reduce employability. The role played by the 'lifestyle' health factors - smoking and drinking - might be more complex, as the way in which these variables relate to employment status and preferring 'almost any job', while significant, differs between datasets.

The scales which the values variables are derived from are now explained in more detail. Leftright scale is a mean score derived from a five point scale on four items where data were available: (1) 'the government should redistribute more from the better off to poorer people'; (2) 'management always try to get the better of employees'; (3) 'ordinary people don't get a fair share of the nation's wealth'; and (4) 'there is one law for the rich and another for the poor'. [ix] A one on this scale signals left-wing values, and a five indicates right-wing values. Authority is a scale where one means authoritarian and five libertarian values. This scale combines two items: (1) 'for some crimes the death penalty is most appropriate'; and (2) 'people who break the law should get stiffer sentences'. Morality is a scale derived from combining two items: (1) 'couples with children should not separate'; and (2) 'marriage is for life'. A score of one indicates agreement, and therefore commitment to traditional morality, while a score of five indicates disagreement, and therefore a liberal stance.

These values are of interest to the models because they associate with employment status (the 'unemployed and seeking work' are found in the NCDS58 and BCS70 to be more likely than those in employment to be left-wing, libertarian and reject traditional morality) and with preferring 'almost any job' (right-wing values, authoritarianism and traditional morality all associate with this preference). While the values variables were included in the models analysis purely because they emerged as important in the initial exploratory analysis, they are nevertheless also, incidentally, of some theoretical interest. This is not only because debates about the supposed 'work shyness' of some unemployed people are highly politicized, as was shown in the introduction, but also because some commentators have suggested that significant numbers of unemployed people lack appropriate values, including those concerning authority and family forms (most famously, Murray, 1990). Indeed, the lifestyle variables, particularly alcohol, are of some theoretical interest in this regard, as some right-wing accounts (including Murray's) have 
portrayed the voluntarily unemployed as irresponsible and hedonistic.

\section{Results}

The analysis begins by examining the distribution of responses to the 'almost any job' item by employment status (see Table 1). Here, strongly agree / agree responses are combined, as are strongly disagree / disagree responses, in order to see patterns in the data more clearly. In all four datasets the percentage of unemployed people disagreeing or strongly disagreeing is more than twice as high as the percentage for employed people. Moreover, in all four waves employed people are much more likely than unemployed people to strongly agree / agree.

Table 1 Here.

Table 1 shows there is no discernible linear pattern for age and preferring 'almost any job', and nor is there any consistent pattern of responses among cohorts across time. The percentage strongly agreeing / agreeing is at its highest for both employed and unemployed people among the 50 year-olds in NCDS58 2008, but at age 42 in 2000 both the currently employed and unemployed categories in the same cohort are less likely to strongly agree / agree than the 30 yearold employed and unemployed people in the BCS70 2000. Perhaps the relatively high percentage of both employed and unemployed agreeing in 2008 reflects respondents' growing awareness of Labour's success in 'making work pay' through its National Minimum Wage and tax credits (see Spicker, 2011: 206-07). It might also be interpreted as symptomatic of growing fears of job scarcity at the onset of recession.

It is important to stress that while unemployment significantly negatively associates with preferring 'almost any job', so too do other predictors. Covariance matrices (see Appendix) show how the outcome and predictor variables are associated with one another. Across all four datasets, not only being 'unemployed and seeking work' but also other variables, including being more educationally qualified, and scoring low on authority and traditional morality measures associate negatively with preferring 'almost any job'. If the unemployed are significantly likelier than employed people to prefer 'being unemployed' to 'almost any job', this begs the question: Do individuals disagree because they are unemployed, or because of their other characteristics? To answer this question we turn to multivariate models which allow us to simultaneously control for various characteristics.

The ordered probit model results (Table 2) shows that, across all four datasets, even when other variables in the model are controlled for, unemployed people are still significantly more likely than employed people to prefer 'being unemployed'. Additionally, the marginal effects for unemployed, presented at the bottom of Table 2, show the change in the predicted probability for a discrete change in the independent variable (in Model 1 the only variable in the model is unemployed, Model 2 is the full model).

In the BCS70, the effect (i.e. the coefficient size) of employment status is decreased by controlling for other variables, whereas in the NCDS58 the effect remains similar when other variables are controlled for. In the bivariate regression models (see Model 1 in Table 2) the coefficients for being unemployed (the effect was always highly significant, at $\mathrm{P}<0.000$ ) were 
-0.77 in the BCS70 1996, -0.70 in the BCS70 2000, -0.83 in the NCDS58 2000, and -0.48 in the NCDS58 2008. As Table 2 shows, the effect for being unemployed in the full models are -0.68 in the BCS70 1996, -0.61 in the BCS70 2000, -0.85 in the NCDS58 2000, -0.54 in the NCDS58 2008 (Models 2 in Table 2). The decreased effect in the BCS70 datasets appears to be partly explained by values: individuals' position on the authority and morality scales are significant variables across all four datasets, and left-right values matter in all but one survey (NCDS58 2008). Individuals who are unemployed and exhibit more right-wing, authoritarian and traditional moral values are more likely to prefer 'almost any job' than those who do not have these values, controlling for all other variables in the models.

Table 2 Here

For the BCS70 1996, education, self-reported health and daily smoking are also significant predictors (Table 2). Individuals with qualifications (including only GCSEs) are significantly less likely than people with no qualifications to prefer 'almost any job'. However, the co-efficient barely increases as level of education increases. Individuals with better self-reported health are more likely to prefer 'almost any job'. Individuals who say they smoke every day are also more likely to prefer 'almost any job' when compared to people who have never smoked.

For the BCS70 cohort in 2000 (Table 2), being unemployed and holding right-wing and traditional moral values remain important predictors, though there is a significant drop in the impact of unemployment for this cohort. Education, self-reported health and smoking lose their significance, and two other variables become significant: gender and drinking most days. These 30 year-old men are significantly more likely to prefer 'almost any job' than 30-year old women. Those who drink most days are also more likely to prefer 'almost any job'. These two effects were absent amongst the same cohort when they were 26 years of age, but it is not clear why.

For the NCDS58 cohort in 2000 (Table 2), there are also a number of consistencies with analysis of the BCS70 datasets. In addition to employment, also right-wing, conservative, and authoritarian values are again significant predictors of preferring 'almost any job'. As with the 26year olds in the BCS70 data-set, heavy drinkers, this time at age 42, are likely to prefer 'almost any job'. Differently from the other datasets, those with a larger household size are more likely to prefer 'almost any job'.

The results are, yet again, similar for the NCDS58 cohort in 2008 (Table 2). Political values and unemployment remain significant predictors. One major exception is that left-wing values no longer matter among the 50 year-olds. As with NCDS70 1996, the analysis indicates that those with excellent self-reported health and, conversely, frequent smokers are most likely to prefer 'almost any job'.

\section{TABLE 3 Here}

The marginal effects (see Table 3 ) confirm that the unemployed are considerably more likely than the employed to disagree with the statement 'having almost any job is better than being unemployed'. For example, when just the unemployed are included as the independent variable for the BCS70 1996, the probability of the entire sample of selecting "strongly disagree" is 
approximately $3 \%(\operatorname{Pr}(1)=.0265)$. In contrast, unemployed people are approximately $9 \%(\mathrm{dy} / \mathrm{dx}=$ .0921) more likely than employed people to select this answer option. Looking at the full model for NCDS58 2000 with all the independent variables included (Model 2), the probability for the entire sample of selecting "agree" is approximately $48 \%(\operatorname{Pr}(4)=.4837)$ and unemployed people are approximately $20 \%(\mathrm{dy} / \mathrm{dx}=-.1966)$ less likely than employed people to select this option.

Overall, the probit models suggest that certain predictors - being unemployed, and scoring highly on the authority and morality scales - hold across the different age cohorts and across time. Nevertheless, there are a number of differences in significant variables across datasets. Qualitative work might provide possible explanations for these differences. Young adults (age 26 in BCS70 1996) are the only group for whom being educated above GCSE level predicts preferring 'almost any job' to 'being unemployed'. While some qualitative research has found that more educationally qualified people are likelier to prefer being unemployed to an unattractive job (Author A, D), it might be that at 26 they are keener to increase their relatively limited employment experience. Along with our oldest respondents (age 50, NCDS58, 2008) for young adults there is also a significant effect for smoking, though it is not clear why. Other noteworthy differences include the following (in each case there is no obvious explanation): only for the 30 year-olds in BCS70 in 2000 is being male a positive significant predictor of preferring 'almost any job' to 'being unemployed'; household size predicts preferring 'almost any job' only for our 42 year olds (NCDS58 in 2000); only amongst the 50 year-olds in NCDS58 2008 do right-wing values fail to act as a predictor.

\section{Conclusion}

Literature on unemployment and attitudes to work has not previously discussed how attitudes are measured. This article argued that the agree / disagree statement 'having almost any job is better than being unemployed' is a good measure for finding out whether unemployed people are generally more likely than employed people to prefer unemployment to an unattractive job (an important question in view of right-wing claims that large numbers of unemployed people remain on benefits for this reason). The analysis of BCS70 / NCDS58 data found that being 'unemployed and seeking work' is an important predictor of 'disagreeing' with the statement in all recent datasets, and in both cohorts, even when relevant variables are controlled for. Libertarian and liberal values also associated strongly with disagreeing across all datasets, and left-wing orientation associated strongly with disagreeing in all age groups except the 50 year-olds in NCDS58 2008. All three of these value scales associated strongly with being 'unemployed and seeking work'.

The finding about the unemployed contrasts sharply with existing studies which asked the 'lottery question' and concluded that unemployed people's employment commitment is at least as strong as employed people's. It is important to note that attitudes research only tells us how people responded to a particular question worded a particular way. Expressed attitudes are not necessarily good predictors of behaviour, and they are sometimes attempts to justify behaviour. While our 70 qualitative interviews generally indicated a strong link between responses to the survey item and actual labour market choices, this was not the case for eight respondents whose responses were based not on their own preferences, but on what they believed people generally should do when deciding between 'almost any job' and 'being unemployed'. Hence, the strong 
association between responses to the survey item and liberal / libertarian / left attitudes might reflect the influence of the political principles Mead (1988) referred to (see p.3). Some people might therefore be applying these principles to others but not to themselves. Furthermore, it is unclear whether respondents' employment status led them to have particular attitudes, or vice versa. Certainly unemployment can be demoralising (see Kelvin and Jarrett, 1985), and our preliminary analysis (see page 11, and endnote V) of the datasets found that the strength of associations between attitudes and employment statuses in different waves of the same survey were reduced by approximately half from what they had been if the same wave of the survey which suggests that some of the negative attitudes towards employment might be a consequence of the experience of unemployment. But even if those who prefer 'being unemployed' to 'almost any job' are more likely to become and remain unemployed, the role played by structural factors in determining people's employment status might nevertheless heavily outweigh the role played by their attitudes to unattractive jobs. Unravelling the relative importance of all these factors would be a worthwhile topic for further research. Here, despite all these considerations, we can nevertheless conclude that published UK research now no longer provides unanimous support for the view that unemployed people's attitudes towards employment are generally at least as positive as employed people's.

Deciding on the policy implications of this main finding is problematic because, as Mead (1988) observed (p.3), the behaviour one insists upon from unemployed benefit claimants depends largely on one's political beliefs. Conservatives might suggest the findings imply that unemployed claimants' job search behaviour should be more closely monitored and controlled. Left commentators, on the other hand, might defend unemployed people's right to eschew unattractive jobs, or insist that tax credits and the National Minimum Wage be increased to make low status employment more attractive and consistent with ideals of social justice.

\section{References}

Atkinson W (2010) Class, Individualization and Late modernity. Basingstoke: Palgrave MacMillan.

Deacon A (2002) Perspectives on Welfare. Buckingham: Open University Press.

Deacon A and Mann K (1999) Agency, modernity and social policy. Journal of Social Policy 28 (3): 413-35.

Dean H and Taylor-Gooby P (1992) Dependency Culture: the explosion of a myth. London: Harvester Wheatsheaf.

Furnham A (1990) The Protestant Work Ethic. London: Routledge.

Furnham A and Bland C (1983) The Protestant work ethic and conservatism. Personality and Individual Difference 4 (2): 205-06.

Gallie D and Vogler C (1994), Unemployment and attitudes to work. In Gallie D, Marsh C and

Vogler C (eds) Social Change and the Experience of Unemployment Oxford: OUP, 115-153.

Gallie D and White M (1993) Employment Commitment and the Skills Revolution. London: PSI.

Glossop C and Shaheen F (2009) Accession to Recession: A8 migration in Bristol and Hull. London: Centre For Cities.

Gregg P and Wadsworth J eds. (2011) The Labour Market in Winter Oxford: OUP.

Hassall S, Muller J and Hassall E (2005) Comparing the protestant work ethic in the employed and the unemployed in Australia. Journal of Economic Psychology 26: 327-41. 
Jordan B, James J, Kay H, and Redley M (1992) Trapped in Poverty? London: Routledge.

Kelvin P and Jarrett J (1985) Unemployment: its social psychological effects Cambridge: Cambridge University Press.

Lindsay C and McQuaid R (2004) Avoiding the 'McJobs': unemployed job seekers and attitudes to service work. Work, Employment and Society. 18 (2): 297-319.

McKay S, Walker R, and Youngs R (1997) Unemployment and Jobseeking before Jobseeker's Allowance. DSS Research Report 73, HMSO.

McRae, S (1987), Young and Jobless, London: PSI.

Marsden D (1982) Workless. London: Croom Helm.

Marsland D (1996) Welfare or Welfare State? London: Macmillan.

Mead L (1988) The hidden jobs debate. The Public Interest 91, Spring: 40-58.

Mirels H and Garrett J (1971) Protestant Ethic as a Personality variable. Journal of Consulting and Clinical Psychology 36: 40-44.

Mokhtar C and Platt L (2010) Lone mothers, ethnicity and welfare dynamics. Journal of Social Policy 39 (1): 95-118.

Murray C (1990) The emerging British underclass. In Lister R (ed) (1996) Charles Murray and the Underclass London: IEA, 23-52.

Pahl R (1994) Balancing all forms of work. In Bryson A and McKay S eds. Is it worth working? London: PSI, 60-76.

Rose M (2005) Do rising levels of qualifications alter work ethic, work orientation and organizational commitment for the worse? Journal of Education and Work 18 (2): 131-64.

Shildrick T, MacDonald R, Webster C and Garthwaite K (2012) Poverty and Insecurity Bristol: Policy Press.

Spicker P (2011) How Social Security Works Bristol: Policy Press.

Tang T and Tzeng J (1992) Demographic correlates of the Protestant work ethic. Journal of Psychology 126 (2): 163-70.

Townsend P (1993) The International Analysis of Poverty Hemel Hempstead: Harvester Wheatsheaf.

Trickey H, Kellard K, Walker R and Smith, A (1998) Unemployment and Jobseeking: two years on, DSS Research Report 87, HMSO.

Walker R with Howard M (2000) The making of a welfare class? Bristol: Policy Press.

White M (1991) Against Unemployment. London: PSI.

Wright S (2012) Welfare-to-work, agency and personal responsibility. Journal of Social Policy 41 (2): 309-28.

Table 1. Distribution of the outcome variable across all four datasets for employed and unemployed

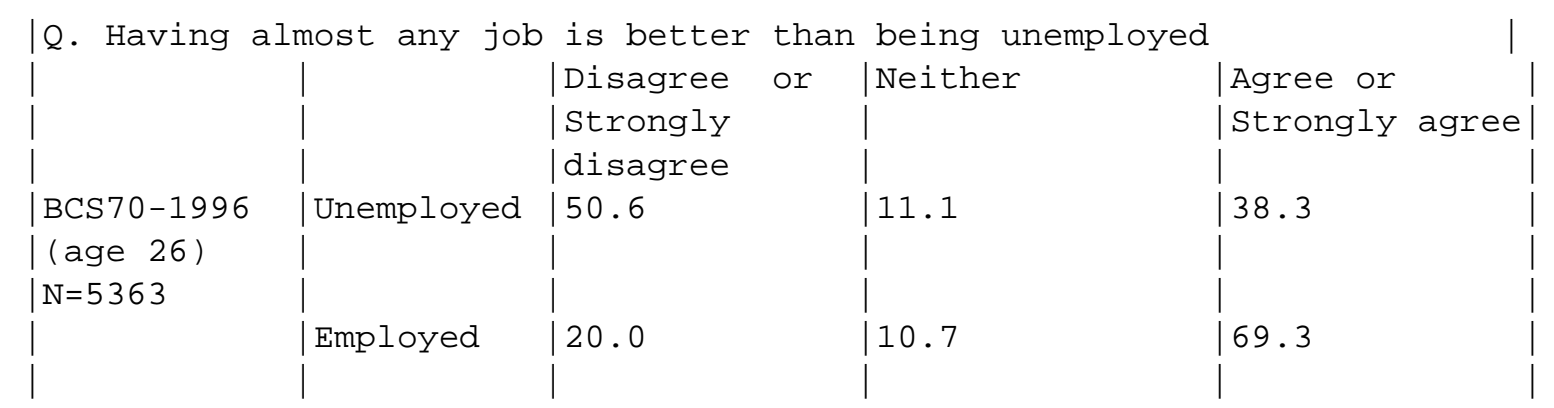




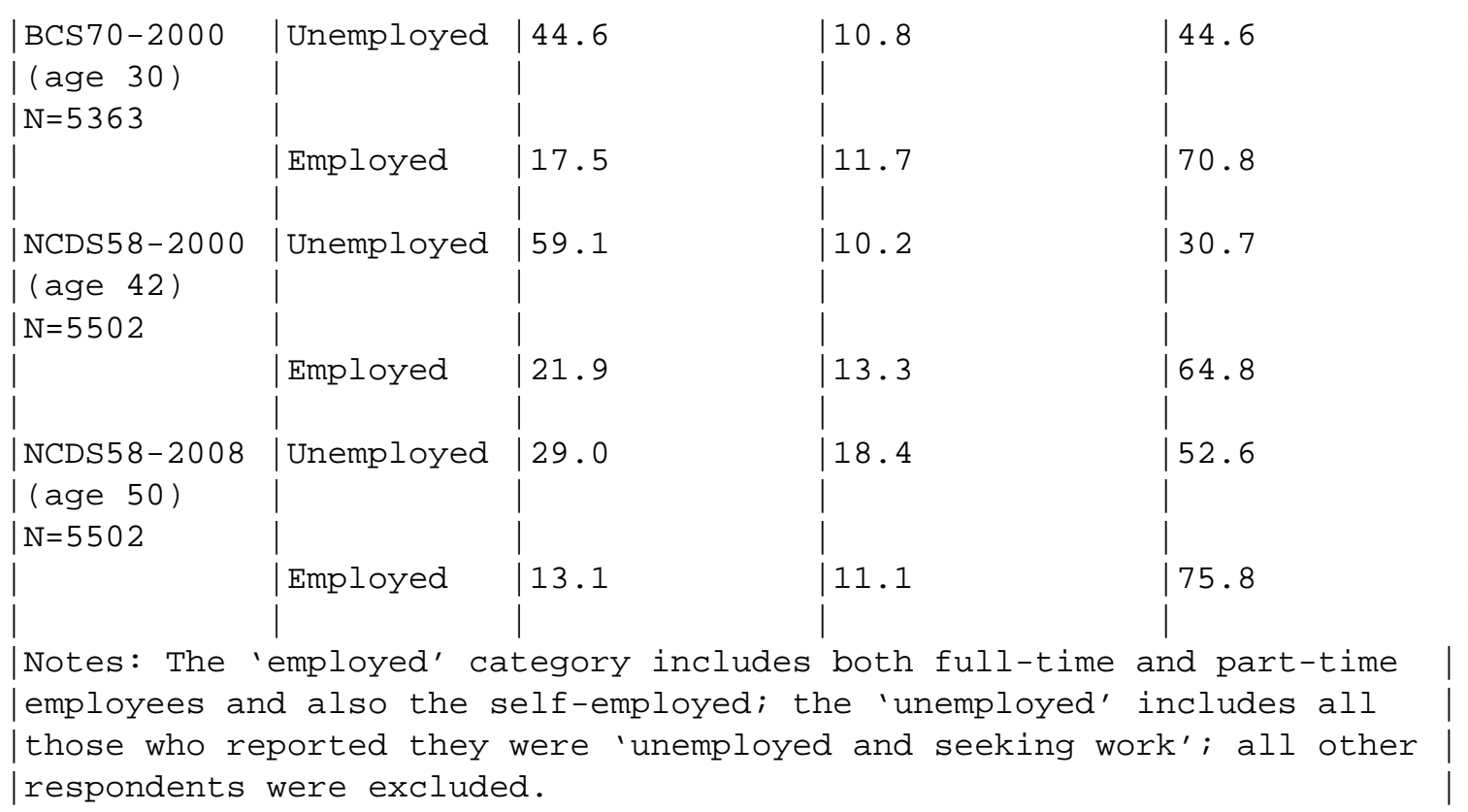

Table 2. Ordered probit regression models predicting agreement with the statement 'having almost any job is better than being unemployed' (strongly disagree, disagree, neither agree nor disagree, agree, strongly agree)

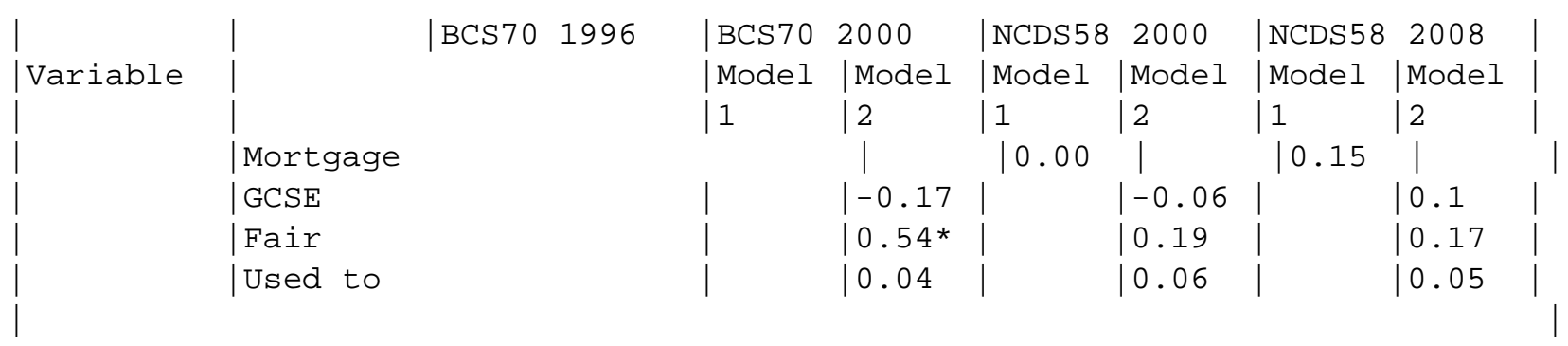


Table 3: Marginal effects for unemployed variable from the ordered probit regression models predicting agreement with the statement 'having almost any job is better than being unemployed' (strongly disagree 1, disagree 2 , neither agree nor disagree 3 , agree 4 , strongly agree 5)

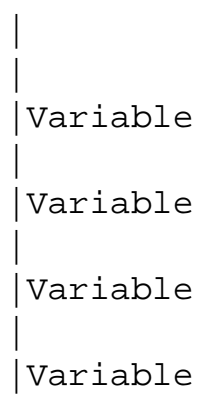

$$
\begin{aligned}
& \text { BCS70 } 1996 \\
& \text { Model } 1 \\
& \mid \operatorname{Pr}(1)=.0265 \\
& \mid \text { Model } 1 \\
& \operatorname{Pr}(1)=.0250 \\
& \mid \begin{array}{ll}
\text { Model } 1 \\
\operatorname{Pr}(1)=.0243 \\
\operatorname{Model~} 1
\end{array}
\end{aligned}
$$




\section{End notes}

\section{[i] See Author $\mathbf{C}$ for a more detailed discussion about survey measures and our understanding of the relationship between attitudes to work and educational attainment.}

[ii] This research was part of a British Academy-sponsored in-depth interview project about people's labour market histories and their attitudes towards employment and unemployment. [iii] Where the survey answer options were comparable but not identical, they were recoded into equivalent categories.

[iv] The most important consideration is that when unemployment is relatively low (as in 2000 and 2008) it is known to be down to a 'hard core' which includes a higher proportion of 'hard to employ' people; when unemployment is relatively high (as in 1996) the unemployed category is typically a more 'random' group in terms of its characteristics and hence more likely to be similar to the employed (White 1991).

[v] 76.4\% of people who were employed and $60.7 \%$ of people who were 'unemployed and seeking work in BCS70 2000 had agreed inork' in BCS70 2000 had agreed in 1996 that 'almost any job is better than being unemployed' (Cramer's V (?c) test of association score $\left.=0.061^{* * *}\right) ; 79.5 \%$ of the employed and $61.4 \%$ of the unemployed in 1996 went on to agree in 2000 (Cramer's V (?c) $=0.087^{* * *}$ ). In the NCDS58, $72.8 \%$ of the employed and $62.7 \%$ of the unemployed in 2008 agreed in 2000 (Cramer's V $(? \mathrm{c})=0.035^{* *}$ ), while $83.3 \%$ of the employed and $72.6 \%$ of the unemployed in 2000 agreed in 2008 (Cramer's V (?c) $=0.039 * * *$ ).

[vi] This is with the exception of 'voting behaviour', which was excluded because its meaning was felt to be more accurately captured by the various attitude scales. The following other variables did not feature in the model because they did not deliver significant associations with the dependent variable (preferring 'almost any job) or with being 'unemployed and seeking work': highest vocational qualification, gendered allocation of domestic chores, tendency to help one's children with homework, tendency to visit one's children's school, attitudes towards education, attitudes towards mothers' employment, and environmentalism. Some of these might well have been excluded from the model at a later stage anyway, if they had low numbers in the 'unemployed and seeking work' category.

[vii] Note that we excluded from the analysis all respondents who were neither in employment nor 'unemployed and seeking work'. Around $10 \%$ of respondents were dropped from the sample because they were either in full-time education, permanently sick or disabled, retired, housewives/husbands or on training schemes. They were left out because debates about unemployment and attitudes to work centre on employed people, unemployed people and transitions between employment and unemployment. We categorised as 'unemployed' only those who gave their employment status as 'unemployed and seeking work' because it is the only status to include the word 'unemployed'.

[viii] Cramer's V (?c) tests of association scores between the outcome variable and self-reported fair/poor health are $0.0715 * * *$ (BCS70 1996), 0.0394*** (BCS70 2000), 0.0144ns (NCDS58 2000) and 0.0569*** (NCDS58 2008). For smoking every day, they are $0.0309 * *$ (BCS70 1996), 0.0290** (BCS70 2000), 0.0203* (NCDS58 2000), 0.0026ns (NCDS58 2008). For drinking alcohol every day, they are 0.0468*** (BCS70 1996), -0.0082ns (BCS70 2000), $-0.0142 \mathrm{~ns}$ (NCDS58 2000) and -0.006ns (NCDS58 2008). However, drinking alcohol every day is negatively associated with being unemployed in both NCDS cohorts. The Cramer's V (?c) measures of association between being unemployed and drinking alcohol every day are -0.0228* (NCDS58 2000) and -0.0194* (NCDS58 2008). $x$ Note that we were unable to construct exactly the same left / right scale for each survey: BCS70 1996 contained only item one, NCDS58 2008 contained only items 2, 3 and four. 
Appendix: Covariance matrices

Co-variance matrix BCS70 1996

|Any job |Unemployed |Male |Household size |Owner |Education |Health |Smoking |Drinking |Leftright |Authority |Morality ||Any job |1.00 | | | | | | | | | | | Unemployed |-0.14* |1.00 | | | | | | | | | | |Male |-0.03* $0.08^{*}|1.00||||||||||| \mid$ Household size |-0.02 |0.05*|0.05*|1.00 || || || |||||Owner $|0.13 *|-0.14|-0.07 *|-0.31 *|1.00||||||||| \mid$ Education $|-0.12|-0.04 *|-0.07 *|-0.11^{*}|-0.08 *| 1.00||$ | | | || |Health |0.088 |-0.04*|0.04*|-0.04*|0.03*|0.09*|1.00 || || || |Smoking |0.00 |0.07*|0.04* $|0.03 *|-0.09^{*}\left|-0.19^{*}\right|-0.15^{*}|1.00||||| \mid$ Drinking $|-0.07 *|-0.03 *\left|0.19^{*}\right|-0.10^{*}\left|-0.09^{*}\right| 0.17^{*}$

$\left|0.05^{*}\right| 0.16^{*}|1.00||||| \mid$ Left-right $\left|0.10^{*}\right|-0.09^{*}|-0.01|-0.06^{*}\left|-0.05^{*}\right| 0.01\left|0.05^{*}\right|-0.05^{*} \mid 0.05$ $|1.00||| \mid$ Authority |-0.24*|0.04*|-0.04*|-0.07*|-0.10*|0.38*|-0.01 |0.02*|0.14|-0.11*|1.00|| $\mid$ Morality |-0.18*|0.01*|-0.08*|-0.04*|-0.08*|0.06*|-0.04*|0.05*|0.09|0.07*|0.18*|1.00||

\section{Co-variance matrix BCS70 2000}

|Any job |Unemployed |Male |Household size |Owner |Education |Health |Smoking |Drinking |Leftright |Authority |Morality ||Any job |1.00 | | | | | | | | | | | |Unemployed |-0.10* |1.00 | | | | | || || | |Male $\left|0.04^{*}\right| 0.04 *|1.00||||||||||| \mid$ Household size $|0.02 *|-0.01\left|0.05^{*}\right| 1.00|||||||||| \mid$ |Owner $\left|0.08^{*}\right|-0.16^{*}\left|-0.06^{*}\right|-0.09^{*}|1.00||||||||| \mid$ Education $\left|-0.04^{*}\right|-0.05^{*}\left|-0.06^{*}\right|-0.20^{*}\left|0.05^{*}\right| 1.00 \mid$

|| || || |Health |0.04*|-0.05*|-0.01*|-0.06*|0.07*|0.11*|1.00 || || || |Smoking |-0.01 |0.10* $\left|0.05^{*}\right| 0.02 *\left|-0.15^{*}\right|-0.19 *\left|-0.18^{*}\right| 1.00|||||| \mid$ Drinking $|0.00|-0.00|0.19 *|-0.13^{*}|0.01| 0.15^{*}$ $\left|0.05^{*}\right| 0.08^{*}|1.00||||| \mid$ Left-right $\left|0.06^{*}\right|-0.11^{*}\left|-0.01^{*}\right|-0.11^{*}\left|0.11^{*}\right| 0.23^{*}\left|0.14^{*}\right|-0.12^{*} \mid 0.13^{*}$ $|1.00||| \mid$ Authority |-0.18*|0.01 |-0.05*|-0.16|-0.05*|0.32*|0.01*|-0.01|0.12*|0.15*|1.00|| |Morality |-0.14*|0.01*|-0.08 |-0.09|-0.07*|-0.00|-0.03 |0.07*|0.04*|0.07*|0.21*|1.00||

\section{Co-variance matrix NCDS58 2000}

|Any job |Unemployed |Male |Household size |Owner |Education |Health |Smoking |Drinking |Leftright |Authority |Morality ||Any job |1.00 | | | | | | | | | | |Unemployed |-0.11* |1.00 | | | | | || | | | |Male $\left|0.04^{*}\right| 0.03 *|1.00||||||||||| \mid$ Household size |-0.00 |-0.05*|0.01*|1.00 || || || || || Owner $|0.00|-0.13^{*}|0.01|-0.10 *|1.00|||||||||||$ Education $\left|-0.05^{*}\right|-0.01|-0.01 *|-0.20 *\left|0.05^{*}\right| 1.00||||||$

| | |Health $|0.02 *|-0.05^{*}|-0.00|-0.06 *|0.07 *| 0.11^{*}|1.00|||||||$ Smoking $|0.01 *| 0.03 * \mid 0.00$ $|0.02 *|-0.15^{*}|-0.19 *|-0.18^{*}|1.00|||||||$ Drinking $|-0.00|-0.02 *\left|0.18^{*}\right|-0.13^{*}|0.00| 0.15^{*} \mid 0.05^{*}$ $\left|0.01^{*}\right| 1.00|||| \mid$ Left-right $\left|0.03^{*}\right|-0.04^{*}\left|-0.08^{*}\right| 0.00\left|0.10^{*}\right| 0.10^{*}\left|0.14^{*}\right|-0.12^{*}\left|0.13^{*}\right| 1.00|| \mid$

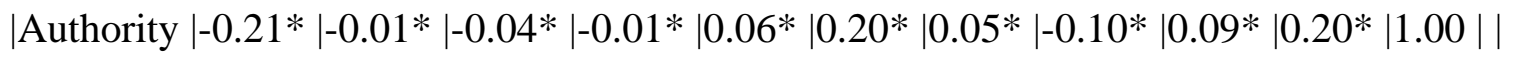
$\mid$ Morality $\left|-0.15^{*}\right| 0.02 *\left|-0.13^{*}\right|-0.18^{*}|-0.04 *| 0.05^{*}\left|0.01^{*}\right| 0.06^{*}\left|0.05^{*}\right| 0.05^{*}\left|0.18^{*}\right| 1.00||$

\section{Co-variance matrix NCDS58 2008}

|Any job |Unemployed |Male |Household size |Owner |Education |Health |Smoking |Drinking |Leftright |Authority |Morality ||Any job |1.00 | | | | | | | | | | | Unemployed |-0.07* |1.00 | | | | || || || |Male |-0.05* |-0.04* |1.00 | | | | | || || || Household size $|0.00| 0.00\left|-0.11^{*}\right| 1.00||||||||||||$ |Owner |$0.00|-0.12 *|-0.01 *|0.03 *| 1.00||||||||||$ Education $|-0.07 *|-0.05^{*}|-0.00| 0.09 *\left|0.13^{*}\right| 1.00||||||$

| | |Health $\left|0.06^{*}\right|-0.06^{*}\left|0.02^{*}\right| 0.03^{*}\left|0.08^{*}\right| 0.14^{*}|1.00|||||||$ Smoking $\left|0.03^{*}\right| 0.05^{*}|0.00|-$ $0.08^{*}\left|-0.15^{*}\right|-0.19^{*}\left|-0.13^{*}\right| 1.00|||||| \mid$ Drinking $|0.00|-0.00|-0.14 *| 0.01|0.08 *| 0.16^{*} \mid 0.11^{*}$ $|0.02 *| 1.00|||| \mid$ Left-right $|-0.03 *|-0.05 *|0.07 *| 0.04 *|0.09 *| 0.29 *|0.17 *|-0.15 *|0.11 *| 1.00||$ 


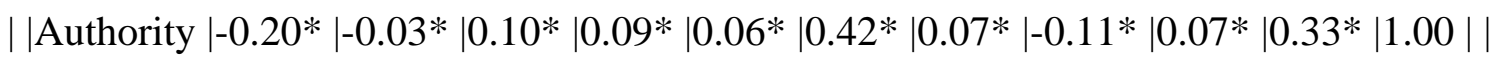

$\mid$ Morality $\left|-0.16^{*}\right|-0.01|0.17 *|-0.12 *|-0.03 *| 0.00|0.02 *| 0.05^{*}|0.02 *| 0.05 *|0.14 *| 1.00||$ 